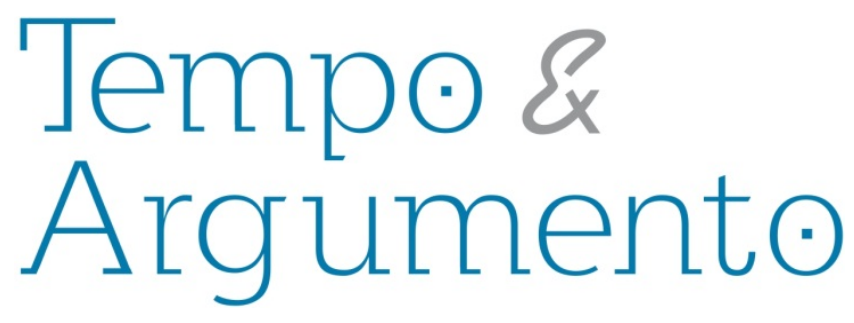

\title{
Vetores para uma escolha: História do Tempo Presente e as pesquisas discentes no PPGH/UDESC
}

\begin{abstract}
Resumo
Este artigo integra a edição comemorativa dos dez anos da criação do Programa de PósGraduação em História da Universidade do Estado de Santa Catarina (PPGH/UDESC), ocorrido em 2007, e que se fez acompanhar, desde 2009, da Revista Tempo \& Argumento. Tem como objetivo: apresentar as escolhas teóricas que balizaram a proposição do programa, com enfoque em História do Tempo Presente; identificar os recortes temporais e geográficos selecionados; as opções metodológicas e os enfoques teóricos privilegiados das dissertações de mestrado defendidas no decorrer deste período. Busca analisar as produções acadêmicas discentes como veículos de disseminação de estudos e debates sob a perspectiva da História do Tempo Presente, um campo em construção na área da História e que tem, na UDESC, o primeiro programa de pós-graduação específico com esta proposição temática.
\end{abstract}

Palavras-chave: História do Tempo Presente. Universidade do Estado de Santa Catarina. Programa de Pós-graduação em História. Estudantes de Pós-graduação.

\author{
Luciana Rossato \\ Doutora em História pela Universidade Federal do Rio \\ Grande do Sul. Professora do Departamento de \\ História, do Programa de Pós-graduação em História e \\ do Mestrado Profissional em Ensino de História da \\ Universidade do Estado de Santa Catarina. \\ Brasil \\ lucianarossato1972@gmail.com

\section{Maria Teresa Santos Cunha} \\ Graduação e Mestrado em História (UFSC) e Doutora \\ em Educação/História e Filosofia pela Universidade de \\ São Paulo. Professora do Departamento de História e \\ dos Programa de Pós-Graduação em História e \\ Pós-Graduação em Educação da Universidade do \\ Estado de Santa Catarina. Bolsista produtividade em \\ Pesquisa do CNPq. \\ Brasil \\ mariatsc@gmail.com
}

\section{Para citar este artigo:}

ROSSATO, Luciana; CUNHA, Maria Teresa Santos. Vetores para uma escolha: História do Tempo Presente e as pesquisas discentes no PPGH/UDESC. Revista Tempo e Argumento, Florianópolis, v. 9, n. 20, p. 162 -185. jan./abr. 2017.

DOI: $10.5965 / 2175180309202017162$

http://dx.doi.org/10.5965/2175180309202017162 


\title{
Vectors for a choice: History of Present Time and the student researches at PPGH/UDESC
}

\begin{abstract}
This article composes the commemorative edition for the 10 years of creation of Graduate Program in History of the Santa Catarina State University (PPGH/UDESC). The program started its activities in 2007, and has been accompanied, since 2009, by Tempo \& Argumento Journal. Its purpose is to present the theoretical choices that guided the program's proposal with a focus on the History of Present Time, to identify the selected temporal and geographic clippings, the methodological options and the privileged theoretical approaches of the dissertations defended during this period. The study aims to analyse the student academic productions as vehicles to the dissemination of studies and debates from the History of the Present Time perspective, a field under construction in the History area which has, at UDESC, the first Graduate Program specific with this thematic proposition.
\end{abstract}

Keywords: History of the Present Time. Santa Catarina State University. Graduate Program in History. Graduate Students.

\begin{abstract}
A História não é somente o estudo do passado; ela também pode ser, com um menor recuo e métodos particulares, o estudo do presente. [...] A epistemologia da história do presente consiste, portanto, em interrogar a história a fim de propor novos dados que aumentarão sua capacidade de explicitação e sugestão (CHAUVEAU, A.; TÉTART, P., 1999, p. 15 e 36).
\end{abstract}

\section{Configurações iniciais}

A opção pela temática sobre a História do Tempo Presente foi motivada, inicialmente, por algumas escolhas: reconhecimento das leituras referentes à historiografia francesa, produzida no decorrer das décadas de 1970-1980, que enfatizavam a história do político e do presente (RÉMOND, 2003) e se concretizaram na 
criação do Institut d'Histoire du Temps Présent (IHTP)'; o acesso digital a redes espanholas sobre a História do Presente ${ }^{2}$, bem como as leituras e discussões das análises de historiadores nacionais, como as de Marieta de Moraes Gomes Ferreira ${ }^{3}$ e Helenice Rodrigues ${ }^{4}$, além das reunidas, desde 1994, no Laboratório de Estudos do Tempo Presente do Instituto de Filosofia e Ciências Sociais da UFRJ (Universidade Federal do Rio de Janeiro $)^{5}$ e as discussões feitas, desde 2010, pelos Cadernos do Tempo Presente, editado pela Universidade Federal de Sergipe. ${ }^{6}$ Outra motivação para a escolha se deve à possibilidade de um recorte temporal para trabalhar a História como um campo de estudos que comporte construções interpretativas dos processos e eventos que tiveram, ou têm lugar, mais especificamente a partir da segunda metade do século XX e no início deste século XXI. Deve-se, igualmente, às possibilidades de percorrer novas aspirações que permitiam uma fértil interlocução da história com outras áreas de conhecimento, por se entender que, desse modo, ela deixaria de ser mero repositório de experiências para constituir-se em campo de reflexão sobre os usos do passado pelo presente, de modo a ultrapassar tradicionais fronteiras disciplinares pela possibilidade de dialogar com estes historiadores. Este propósito tem por base o entendimento de Bédarida, que ele assim formula:

a história do tempo presente, mais do que qualquer outra, é por natureza uma história inacabada: uma história em constante movimento, refletindo as comoções que se desenrolam diante de nós e sendo portanto objeto de uma renovação sem fim (BÉDARIDA, 1996, p. 229).

\footnotetext{
${ }^{1}$ Fundado em 1978 e inaugurado em 1980 como Laboratório do Centro Nacional de Pesquisa Cientifica da França (CNRS), o IHTP esteve sob a direção de François Bédarida até 1990. Na sequência, foi coordenado por Robert Franck e Henry Rousso. Ver artigo: MEDEIROS, Sabrina Evangelista. Da Historiografia Francesa ao Tempo Presente. Disponível em: http://www.hcomparada.historia.ufrj.br/ revistahc/artigos/volume001 Numo02 artigoo01.pdf. Acesso em: 25 abr. 2017.

${ }^{2}$ A saber: Associación de Historia Actual (AHA) (www.historia-actual.com); Associación de Historiadores del Presente (www.historiadelpresente,com); Historia a Debate (http://h-debate.com/), todas citadas por SILVA, Cristiani Bereta da. Escrever Histórias do Tempo Presente: algumas questões e possibilidades. Tempos Históricos. M. C. Rondon, v. 9. p, 257-276, 2. sem. 2006.

${ }^{3}$ FERREIRA, Marieta de Moraes. História, Tempo Presente e História Oral. Topoi, Rio de Janeiro, n. 5, v. 3, p. 314-332, jul./dez. 2002. Disponível em: http://www.revistatopoi.org/numeros anteriores/topoi05/topoi5a13.pdf Acesso em: $1^{\circ}$ mai. 2017.

${ }^{4}$ RODRIGUES, Helenice. "História do Tempo Presente: Problemática das Fontes" (2001). Disponível em http://www.poshistoria.ufpr.br/fonteshist/Helenice.pdf Acesso em: 29 abr. 2017.

${ }^{5}$ http://www.dhi.uem.br/labtempo/index.php?option=com_content\&view=article\&id=49\&ltemid=57

${ }^{6}$ Ligado ao Grupo de Estudos do Tempo Presente (GET) do Departamento de História da Universidade Federal de Sergipe(UFS) e em atividade desde 2010. Em 2017 foi publicado o volume 26. Disponível em: https://seer.ufs.br/index.php/tempo/issue/view/534.
} 
Isto é que nos levou a escolher como vetores centrais para a efetivação desta proposta, entre outros fenômenos, as culturas políticas e sociabilidades tecidas no seu decorrer, além das linguagens e identificações - sob forma de leituras e traduções do contemporâneo -, configuradas de maneira a emprestar inteligibilidade aos recursos materiais e simbólicos que amparam e fornecem as distintas representações do vivido e do viver, e Ihes dão visibilidade. A escolha por esta vinculação temática visa discutir questões conceituais relacionadas ao tempo presente, como: campo constitutivo, múltiplas temporalidades, diversidade temática, pluralidade documental e de procedimentos de pesquisa, nos quais se conjugam processos sociais e regimes de historicidade, memórias e vivências, individuais ou coletivas, como processos essenciais à construção do conhecimento histórico. Para tanto, buscou-se abranger estudos que movimentassem, entre outros fenômenos, interlocuções sobre a relação memória, esquecimento, regimes de historicidade, além de tornar inteligíveis os recursos materiais e simbólicos que amparam e tornam visíveis as distintas representações do vivido e do viver no campo da pesquisa em história?.

Cabe ressaltar que, neste momento inicial do Proframa de Pós-Graduação em História da Universidade do Estado de Santa Catarina - PPGH/UDESC ${ }^{8}$, foram traçados dois eixos de investigação, materializados em duas linhas de pesquisa ${ }^{9}$ que se pautaram pelas temáticas e interesses dos docentes. A linha Culturas Políticas e Sociabilidades,

\footnotetext{
7 Vale ressaltar que, na primeira seleção ao PPGH/UDESC, em 2006, foram indicados como leitura obrigatória os seguintes livros: BURKE, Peter. História e teoria social. São Paulo: Editora da UNESP, 2002; CERTEAU, Michel de. A invenção do cotidiano: artes de fazer. Petrópolis/RJ: Vozes, 1994; CHAVEAU, Agnès; TÉTART, Philippe (Orgs.). Questões para a história do presente. Bauru/SP: EDUSC, 1999; FOUCAULT, Michel. Microfísica do Poder. Rio de Janeiro: Graal, 1986; HOBSBAWM, Eric. Sobre História. São Paulo: Companhia das Letras, 1998.

${ }^{8}$ Compunham, em 2007, o corpo docente inicial do PPGH os professores Cristiani Bereta da Silva, Emerson César de Campos, Gláucia de Oliveira Assis, Luiz Felipe Falcão, Mara Rúbia Sant’Anna, Márcia Ramos de Oliveira, Maria Teresa Santos Cunha, Maurício Aurélio dos Santos, Marlene de Fáveri, Norberto Dallabrida, Paulino de Jesus Francisco Cardoso, Reinaldo Lindolfo Lohn, Sérgio Schmitz e Sílvia Maria Fávero Arend (Coordenadora).

${ }^{9}$ Linha de Pesquisa Culturas Políticas e Sociabilidades e Linha de Pesquisa Linguagens e Identificações. Durante o ano de 2016, uma comissão, formada pelos professores Janice Gonçalves, Cristiani Bereta da Silva (coordenadora), Reinaldo Lindolfo Lohn e Maria Teresa Santos Cunha, discutiu um novo desenho curricular para o PPGH/UDESC e acordou que fossem mantidas estas duas linhas iniciais, mas criaram uma terceira linha de pesquisa, intitulada Politicas da Memória e Narrativas Históricas, em vias de implantação.
} 
relativas à esfera da família, aos movimentos sociais, às instituições (principalmente escolares), às culturas urbanas contemporâneas e aos movimentos sociais e de trabalhadores.

Por outro lado, a atual emergência de temas como memória/esquecimento, patrimônios, mídias, aparência, música, práticas de leitura e cultura escrita, dentre outros fenômenos contemporâneos que alargam seus espaços de ação a partir de formalizações que são, sobretudo, do campo do simbólico, passaram a constituir a linha de pesquisa Linguagens e Identificações.

Estas duas linhas apresentam-se integradas por envolverem variadas linguagens e sociabilidades como ferramentas que, no tempo presente, nos propõem perguntas/questões cujas possibilidades de interpretação podem ser construídas sobre uma alteridade, sobre algo que se passou com o outro, sobre experiências lidas, vividas, sentidas, ouvidas e por meio das quais um grupo, uma classe social, uma população, se reconhece e se faz reconhecer em sua historicidade.

O campo de pesquisa sobre o qual o programa se alicerça, portanto, contempla a constituição dos significantes que, produzindo sentidos, constroem uma história do tempo presente levando seus investigadores a se perguntar por que seus objetos, ao produzirem imagens e representações do contemporâneo, não oferecem verdades aceitáveis, explicações testadas, mas aproximações sucessivas com o viver e suas instigantes operações estéticas, linguísticas e, consequentemente, ligadas ao campo histórico.

\section{Linhas de Pesquisa: a construção de uma legitimidade epistemológica}

Todo ato histórico se realiza com base na experiência e na expectativa dos agentes. Ambas as categorias são apropriadas para tratar do tempo histórico, pois o passado e o futuro se entrelaçam na presencialidade da experiência e da expectativa (KOSELLECK, 2014, p. 307). 
A necessidade de situar acontecimentos (fatos), de datar decisões, de construir legitimidades para abordar o tempo e a pesquisa no tempo, de não raro recuar até outros tempos fez com que se adotasse a noção de regimes de historicidade de Hartog, para quem:

Formuladas a partir de nossa contemporaneidade, as relações que uma sociedade estabelece com o tempo caracterizam um regime de historicidade [...] e o historiador, por lidar com vários tempos, instaurando um vaivém entre as relações respectivas do presente, do passado e do futuro operacionaliza a possibilidade de construção de histórias (HARTOG, 2013, p. 37-39).

Conceito importante nos trabalhos por conter o fator tempo como alvo de estudos e debates, o regime de historicidades foi movimentado em diálogo com as obras de Paul Ricoeur ${ }^{10}$. Assim, pode-se considerar que as pesquisas efetuadas nestas linhas de pesquisa sinalizam para estudos cujos campos de conhecimento se interpenetram e fornecem vetores para compreender o passado/presente/futuro. As duas linhas sustentam, até o momento, o PPGH/UDESC e aqui serão explicitadas a partir do texto elaborado pelos professores que propuseram o programa e o submeteram à aprovação da CAPES $^{11}$.

\subsection{Linha de Pesquisa: Culturas Políticas e Sociabilidades}

A constituição desta linha de pesquisa ampara-se no conjunto de contribuições em torno das abordagens sobre a história do tempo presente que apontam para o chamado retorno do político como inflexão importante na análise histórica, voltada à imponderabilidade dos processos sociais contemporâneos, que demandam um campo

\footnotetext{
${ }^{10}$ Em particular, as obras Tempo e Narrativa, v.. 3 (2010) e A memória, a história, o esquecimento (2007).

${ }^{11} \mathrm{~A}$ descrição das linhas de Pesquisa que compõe o processo de criação do curso enviado à Capes para análise obteve aprovação através Ofício $n^{\circ}$. 718-11/2006/CTC/Capes. O PPGH, da Udesc, foi aprovado como Curso de Mestrado pela Coordenação de Aperfeiçoamento de Pessoal de Nível Superior (Capes) em julho de 2006. No início do ano seguinte, em 17 de janeiro de 2007, foi reconhecido pelo Ministério da Educação (Portaria n.73). A homologação do reconhecimento pelo Conselho Nacional de Educação e o reconhecimento pelo Conselho Estadual de Educação ocorreram em 2008, respectivamente nos meses de setembro e outubro. Entre os anos de 2007 e 2013, o programa manteve apenas o curso de mestrado. O curso de doutorado em História foi oficialmente criado pela Resolução do Conselho Universitário n. 031/2013, de 4 de julho. Em setembro de 2013, a Capes informou a aprovação da proposta, com nota 4. Em 8 de abril de 2014, pela Resolução n.139, o Conselho Estadual de Educação de Santa Catarina reconheceu o curso de doutorado.
} 
novos padrões de comportamento ou de configurações de família, tornaram imprescindíveis abordagens capazes de colocar a questão do poder e da vida pública em outras bases.

Esta linha situa seu enfoque num espaço de tensão marcado pelas sociabilidades que fornecem novos sentidos ao campo político. Estudos recentes, no âmbito das Ciências Sociais, têm destacado um conjunto de novas relações sociais, flexíveis e desengajadas, resultantes de processos de reestruturação produtiva e alterações no mundo do trabalho, provocadas pela volatilidade das formas de acumulação do capital, que resultariam num retraimento despolitizado de indivíduos e grupos em busca de segurança, evitando os espaços públicos, os conflitos e as heterogeneidades.

Tanto quanto no caso da categoria "poder", porém, deve-se considerar que o “político" sofreu deslocamentos importantes, sobretudo pela mudança de perspectiva analítica, não mais centrada exclusivamente no Estado e em seus aparatos de repressão, dominação e legitimação. Dessa forma, há um alargamento do político, envolvendo campos discursivos, representações e experiências elaboradas nas interações sociais, ou seja, nas redes e espaços de sociabilidade, mediante tramas que evidenciam a articulação problemática entre cultura e política como esferas interseccionadas, cuja historicidade se manifesta em diferentes âmbitos, como as ações estatais, as políticas públicas, as questões étnicas, as de geração e gênero, as relativas à esfera da família, às culturas urbanas contemporâneas e aos movimentos sociais e de trabalhadores. A chamada “politização da vida", evento decisivo da modernidade, ganha novos contornos e aponta para outras maneiras de discernir as ações individuais e coletivas contemporâneas.

Compreende-se, então, que há um composto de culturas políticas compreendido pela tessitura das relações sociais, do que decorre, não necessariamente, o retorno de uma história política, mas a ênfase de uma história do campo político e da dimensão política dos fenômenos socioculturais, incrementando análises sobre objetos tão diferentes quanto os grupos populares, as populações afrodescendentes, as elites, as 

trabalham nesta linha de pesquisa para atribuir significados às sociabilidades dispersas e aos horizontes de expectativa de diversos grupos sociais.

Diante desse quadro, a intenção de associar historicamente culturas políticas e sociabilidades pressupõe, em termos teórico-metodológicos, que o campo político não se reduz a mera instância ou domínio delimitado, tampouco a uma superestrutura. Ao contrário, ele é entendido como um domínio que situa as relações sociais e suas representações numa dada historicidade, de maneira a captar a complexidade do tempo presente e a dar relevo às relações de forças desiguais nele existentes, que compreendem práticas sociais que jogam com os sistemas instituídos através de simulações, ou reciprocidades, que podem sugerir submissão e legitimação automática, mas são, antes, manobras e astúcias cotidianas para sobreviver e para inventar espaços de autonomia.

A interface com as sociabilidades, compreendidas como redes de interações que promovem intercâmbios sob determinadas condições históricas e padrões culturais, é o que define a especificidade desta linha de pesquisa, tendo em vista as dificuldades de convivência em um mundo saturado por diferenças. Ganham corpo, assim, temáticas como a chamada globalização e suas implicações culturais, as novas relações tempo/espaço, a descorporificação do trabalho e as relações de poder desterritorializadas, a redução da democracia a disputa eleitoral, a afirmação de novas práticas de controle e vigilância e as novas hierarquias sociais. Nesta perspectiva, esta linha, dedicada às culturas políticas e as sociabilidades, interage com a outra, que integra o programa pela convicção de que as leituras e as traduções do contemporâneo são também produtoras de códigos que dão acesso às formas coletivas e individuais de existência. 
Dentre as diversas implicações do tempo presente está a possibilidade de dele se produzirem leituras e traduções - materializadas em linguagens e identificações -, a fim de se perceber como se integra nos repertórios sensoriais e nos sistemas cognitivos que procuram emprestar-lhe alguns sentidos, mesmo que transitórios. Os procedimentos voltados a elaborar estas leituras e traduções representam tanto uma disponibilidade para desenvolver experiências estéticas inusitadas, quanto uma disposição para decodificar e recodificar, incessantemente, a miríade de signos mediante os quais homens e mulheres passaram a tecer contatos. Em outras palavras, linguagens e identificações constituem, portanto, uma parte do amplo estoque de respostas em face das evidências da complexidade deste mundo e se configuram como tramas, composições, arquiteturas engenhosas que objetivam decifrar os acontecimentos e os processos históricos em que se inscrevem.

Trata-se de linguagens, em especial numa sociedade com elevada oferta de informações visuais, que não podem ser reduzidas ao exercício de percorrer com a vista uma paisagem rascunhada ou rematada e dar-lhe sentido como se fosse um texto escrito graças à aprendizagem de um idioma qualquer. Em verdade, elas sempre recorrem à sensibilidade para captar, filtrar e incluir sinais num conjunto relativamente coerente (memória, imaginário ou intelecção), organizando-os, disponibilizando reações tópicas ou genéricas a eles associadas, o que conforma dimensões que não se restringem à figuração, nem à assimilação do texto escrito, dando ensejo a combinados semânticos móveis e inesperados, como os cenários dos caleidoscópios.

Identificações rompem com as identidades únicas e permitem pensar em diferentes articulações para expressar diversas representações de mundo e distintas problematizações das subjetividades ligadas ao contemporâneo.

De acordo com isto, esta linha de pesquisa intenta fomentar e amparar estudos em nível de pós-graduação e por meio de um diálogo estreito, e sempre renovado, com outros campos disciplinares (como a Antropologia, a Semiologia ou a Teoria Literária), em condições de contribuir para o entendimento dos intrincados eventos históricos transcorridos ao longo do século passado ou em desdobramento no início deste novo século. Para tanto, aglutina docentes cujos interesses de investigação se espraiam por 
temáticas distintas, mas integradas por diferentes linguagens que buscam ler e traduzir cidades, identificações culturais, imigração, memória, mídia, moda, música, práticas de leitura e cultura escrita, dentre outros fenômenos contemporâneos. Esta linha, por conseguinte, possui uma série de interseções com a outra, constante do programa, intitulada Cultura Política e Sociabilidades, não apenas devido à conformidade de alguns objetos de pesquisa (como cidade e memória, para tomar apenas dois deles) e à convergência de algumas abordagens ou enfoques metodológicos, mas, notadamente, porque leituras e traduções do contemporâneo se inscrevem no âmbito da construção de sociabilidades e têm por escopo abarcar a dimensão política inerente a todo e qualquer processo histórico, a toda e qualquer produção sociocultural de homens e mulheres em sua desacomodada vivência.

\section{Dissertações defendidas e as perspectivas de aproximação ao Tempo Presente}

Entre 2008 (ano da primeira defesa) e 2016, foram defendidas 121 dissertações. Destas, 47 foram desenvolvidas na linha de pesquisa Culturas Políticas e Sociabilidades e 74, na linha de pesquisa Linguagens e Identificações ${ }^{12}$.

O recorte temporal privilegiado pelas dissertações, como não poderia deixar de ser, contemplam majoritariamente as temporalidades ligadas ao tempo presente explicitadas pela proposta. Assim, a maioria desses trabalhos tem como recorte temporal temas a partir dos anos 1970 do século XX. Algumas delas, ainda que minoritariamente (5), têm como recorte temporal a primeira metade do século $X X$, embora se preocupem em escandir o tempo, abarcando aspectos do presente até a segunda metade do século XX. Como os recortes, devido a diversidade de temas e a problemas pesquisados, são os mais variados, podemos estabelecer os seguintes grandes recortes temporais: das que contemplam o período da ditadura militar (18 dissertações), às que cobrem os anos 1980 (15 dissertações) e, enfim, àquelas cujo recorte se restringe ao século XXI (17

\footnotetext{
${ }^{12}$ Pesquisa realizada no site do programa e referem-se às defesas realizadas de 2008 a 2016. Disponível em: http://www.faed.udesc.br/?id=28 Acesso em: 31 mar. 2017. Colaboraram, na coleta dos dados, os acadêmicos Karla Simone Willemann Schutz (PPGH/ doutoranda), Nathália J. Hermann, Gabriel Dalapria, Julia Paredes e Isadora Muniz Vieira/ Bolsistas de Iniciação Científica do Curso de História/FAED/UDESC.
} 
No que se refere ao recorte geográfico, temos as seguintes características: 62 dissertações têm como foco o estado de Santa Catarina, enquanto somente 7 dissertações se referem a outros estados, com preponderância de estudos sobre o Paraná. Ao cruzar estes dados com o estado de formação inicial dos mestrandos do programa, constata-se que a maioria deles é ou nascida no estado de Santa Catarina, ou nele mora, o que permite uma explicação mais causal sobre o recorte geográfico escolhido. Entre as cidades catarinenses privilegiadas nas pesquisas estão Florianópolis, Joinville, Criciúma e a região conhecida como Vale do Itajaí.

Um conjunto de dissertações pode ser classificado por seu recorte internacional (8 dissertações), o que se explica pelos trabalhos que se referem a migrações. Além disso, também há um conjunto de 21 dissertações de recorte geográfico mais amplo, uma vez que se baseiam em fontes cuja circulação ocorreu em todo o Brasil, como, por exemplo, as relativas ao estudo dos impressos, como revistas semanais e produções audiovisuais.

A linha de pesquisa Culturas Políticas e Sociabilidades iniciou-se com oito docentes $^{13}$. No decorrer desses dez anos de atividades, incorporou mais profissionais; atualmente conta com dez docentes no mestrado ${ }^{14}$, sete dos quais também atuam no doutorado, aprovado pela Capes em 2013, iniciando-se a primeira turma em 2014. A distribuição de orientandos entre os docentes é equilibrada, variando de seis a nove defesas levadas a cabo pelos docentes iniciais do programa. Dois deles desvincularam-se do programa. Dos que se inseriram posteriormente, um orientou cinco defesas; outro, uma, e dois ainda não levaram a cabo nenhuma defesa. Há, também, o caso especifico de um docente que, apesar de pertencer ao grupo inicial do programa, teve duas defesas levadas a termo devido ao seu afastamento temporário do programa. Salienta-se que

\footnotetext{
${ }^{13}$ Docentes iniciais: Cristiani Bereta da Silva, Maurício Aurélio dos Santos, Marlene de Fáveri, Norberto Dallabrida, Paulino de Jesus Francisco Cardoso, Reinaldo Lindolfo Lohn, Sílvia Maria Fávero Arend e Sérgio Schmitz.

${ }^{14}$ Foram credenciados os docentes Luciana Rossato, Mariana Rangel Joffily, Rogério Rosa Rodrigues e Claudia Mortari. Aposentaram-se Sérgio Schmitz e Maurício Aurélio dos Santos.
} 
dissertações que têm como tema instituições escolares, processos de escolarização (entre os anos de 2007 e 2010) e ensino de história.

No que se refere às fontes, salienta-se que uma das características do tempo presente são a diversidade e a quantidade de vestígios do passado disponíveis para o historiador. Nos mais variados suportes, do papel à internet, do texto à imagem em movimento, o historiador do tempo presente corre o risco de ser soterrado pelos vestígios se não delimitar devidamente seu problema de pesquisa. Esta ampliação exponencial dos vestígios, das marcas de passagem do ser humano, possibilitou a ampliação das abordagens do passado nas pesquisas historiográficas. Isto se deve não somente à produção material e à preservação desta produção devido à proximidade temporal, como à ampliação da noção de documento histórico ocorrida com as mudanças na concepção de história a partir das discussões levadas a cabo pela Escola dos Annales, e as que se lhe seguiram. No final do século XX, novas mudanças, entre as quais o avanço da tecnologia, trouxeram novos desafios e possiblidades para o trabalho do historiador. A tecnologia possibilitou o acesso a documentos sem a necessidade de se deslocar até o espaço físico de sua guarda. A possibilidade de pesquisas com novas metodologias, como as pesquisas quantitativas e seriais, fez emergir novas linguagens, além de propiciar novos usos. Com o advento da internet, surgiram também novos documentos até então inexistentes, como blogs, sites, redes sociais, afora as novas formas de relações de trabalho e sociabilidade (JANOTTI, 2005).

Nas 47 dissertações defendidas na linha de pesquisa Culturas Políticas e Sociabilidades ${ }^{15}$, uma das características predominantes é a diversidade de tipologia de fontes utilizadas. Em 27 delas constava, no resumo, que a pesquisa tinha como corpus documental três ou mais tipos de documentos. Em 20, a imprensa (jornais e revistas) foi

\footnotetext{
${ }^{15}$ A análise das dissertações foi feita através da leitura dos resumos e palavras-chave disponíveis na plataforma Sucupira, e da leitura do sumário das dissertações disponíveis no site do programa: http://www.faed.udesc.br/?id=2229.
} 
citada como a documentação preponderante. Em dez, foi utilizada a metodologia da história oral.

Também merecem menção as pesquisas que optaram pelo uso de documentos produzidos pelas instituições do Estado (nove dissertações) e pelo uso de fontes do Judiciário (quatro dissertações). No caso das fontes impressas, salienta-se que dez dissertações defendidas tiveram como problema de pesquisa as narrativas produzidas pelos órgãos da imprensa, entre os quais jornais diários locais de Santa Catarina, como 0 Estado, e revistas nacionais e semanais, como Veja e IstoÉ. Segundo Tania de Luca (2005, p. 118), a partir da década de 1970, o estatuto da imprensa sofreu um deslocamento fundamental: “Ao lado da História da imprensa e por meio da imprensa, o próprio jornal tornou-se objeto da pesquisa histórica." Este conjunto de trabalhos (defendidos entre 2012 e 2016) vincula-se a uma pesquisa coletiva desenvolvida por cinco professores da linha que conseguiu aprovação, junto ao CNPq, dos projetos de pesquisa: Um país impresso: entre culturas políticas e sociabilidades: revistas semanais, projetos sociais $e$ memória histórica no Brasil (1964-1990) ${ }^{16}$ e Um país impresso: revistas semanais, democracia, política e cultura no Brasil (1970-1990) ${ }^{17}$.

O primeiro projeto teve como objetivo investigar:

a construção de representações sociais relativas às adesões de amplas camadas da população brasileira a formas de poder político, práticas coletivas e individuais, imaginários e simbolismos. Parte-se do pressuposto de que tais representações sociais, que conformaram imagens e discursos, são imprescindíveis para a compreensão histórica do papel dos meios de comunicação na produção de efeitos de verdade e difusão de relações de força através de imagens e discursos (AREND, 2011, p. 1).

${ }^{16}$ CNPq - Edital 14/2011 - Universal. Projeto coordenado pela professora dra. Silvia Fávero Arend. Integrantes: dra. Cristiani Bereta da Silva; dra. Luciana Rossato; dra. Marlene de Fáveri; dr. Paulino de Jesus Francisco Cardoso e dr. Reinaldo Lindolfo Lohn. Além dos professores, graduandos e mestrandos também fizeram parte da equipe de pesquisa.

${ }^{17}$ CNPq - Edital 43/2013 - Ciências Humanas, Sociais e Aplicadas. Projeto coordenado pelo professor dr. Reinaldo Lindolfo Lohn. Integrantes: dra. Cristiani Bereta da Silva; dra. Luciana Rossato; dra. Marlene de Fáveri; dr. Paulino de Jesus Francisco Cardoso e dra. Silvia Fávero Arend. Além dos professores, graduandos e mestrandos também fizeram parte da equipe de pesquisa. 
Para o desenvolvimento da pesquisa, foram selecionadas como corpus documental cinco revistas semanais e mensais de circulação nacional: Veja, IstoÉ, Visão, Manchete e Realidade. Este projeto resultou num livro coletivo publicado em $2014^{18}$.

O segundo projeto, em continuação ao primeiro, teve como objetivo problematizar:

representações e memórias em disputa sobre a sociedade brasileira entre 1970 e 1990, por entender que a construção do que viria a ser o regime democrático brasileiro envolveu experiências individuais e coletivas por meio de permanências, rupturas e tensões, mas também conjugou a elaboração de uma narrativa sobre o país e sobre a sociedade brasileira como um todo, em suas pretensas características socioculturais e marcos históricos reconhecidos, com a afirmação do que seriam seus traços em termos de relações políticas, de gênero, étnicas e em termos de estratificação social (LOHN, 2013, p. 1-2).

Este projeto também resultou num livro coletivo, publicado em $2016^{19}$.

A partir da análise dos resumos das dissertações, identificamos os temas mais recorrentes, bem como os conceitos mais acionados para fundamentar as pesquisas desenvolvidas nesta linha de pesquisa. Entre os temas, identificamos sete grandes grupos. Esta classificação é arbitrária e diz respeito às opções das autoras em face do corpus documental desta pesquisa, em cruzamento com as trajetórias acadêmicas dos professores que integram esta linha.

Um primeiro tema, como já salientado, refere-se aos estudos relacionados à imprensa, que totalizam dez dissertações ${ }^{20}$. Diferentemente dos outros temas, que se podem vincular a um ou a dois orientadores, este conjunto de dissertações foi orientado por pelo menos cinco professores, o que mostra o caráter coletivo destas pesquisas, em decorrência dos projetos desenvolvidos com o financiamento do CNPq.

Outro grupo são as pesquisas que tratam de temas como família, infância, juventude e as políticas públicas, que totalizam oito dissertações. Pesquisas que tratam

\footnotetext{
${ }^{18}$ AREND, Silvia M. Fávero (org.). Um país impresso: História do Tempo Presente e revistas semanais no Brasil - 1960-1980. Curitiba: Editora CRV, 2014. 231p.

${ }^{19}$ LOHN, Reinaldo Lindolfo. História nas bancas de revistas: um país impresso entre representações sociais e culturas políticas. Ponta Grossa: Todapalavra, 2016. 354p.

${ }^{20}$ Estão sendo consideradas aqui somente as pesquisas que têm a imprensa como objeto e fonte e não as que usam a imprensa exclusivamente como fonte.
} 
formas de organização e luta, especialmente em Santa Catarina. Outro conjunto significativo de pesquisas, com cinco dissertações, pode ser agrupado como estudos de gênero. Neste caso, análises a partir dos referenciais teóricos desta categoria também são utilizados em outras dissertações, ainda que de forma tangencial, algumas delas realizadas na linha de pesquisa Linguagens e Identificações. Outros dois temas puderam ser identificados, apesar de sua reduzida produção (quatro dissertações cada); referemse a pesquisas sobre História da Educação, instituições escolares e ensino de história e história urbana e modernização.

A linha de pesquisa Linguagens e Identificações iniciou-se com seis docentes ${ }^{21}$. No decorrer desses dez anos de atividades, incorporou mais profissionais; atualmente, conta com nove docentes no mestrado ${ }^{22}$, oito dos quais também atuam no doutorado, implantado em 2013, ainda sem defesas concluídas. Já foram defendidas 74 dissertações ${ }^{23}$ vinculadas a esta linha. A distribuição de orientandos entre os docentes é equilibrada, variando de sete a nove defesas levadas a cabo pelos docentes da linha, exceto de parte de um docente que levou a defesa 13 orientações, e uma docente, incorporada recentemente, que concluiu três orientações.

Da mesma forma que a linha Culturas Políticas e Sociabilidades, a linha Linguagens e Identificações é marcada por uma diversidade de tipologias de fontes utilizadas. Do total de 74 dissertações, 18 explicitavam em seus resumos que as pesquisas tinham sido realizadas a partir de três, ou mais, tipos de documentos. Em 20, consta ter sido utilizada a metodologia da história oral; para nove, ela foi a documentação preponderante na construção do trabalho de documentação preponderante na construção do trabalho.

\footnotetext{
${ }^{21}$ Docentes iniciais: Luiz Felipe Falcão; Marcia de Oliveira Ramos; Maria Teresa Santos Cunha; Emerson Cesar de Campos; Mara Rúbia Sant'Anna Muller e Glaucia de Oliveira Assis.

${ }^{22}$ Foram credenciados três novos docentes: Janice Gonçalves, Rafael Rosa Hagemeyer e Viviane Trindade Borges.

${ }^{23}$ Pesquisa realizada no site do programa; refere-se às defesas realizadas de 2008 a 2016. Disponível em: http://www.faed.udesc.br/?id=28 Acesso em: 31 mar. 2017.
} 
Há documentos que passaram a ser utilizados de modo mais sistemático pelos historiadores somente a partir das últimas décadas do século XX e início do século XXI: produções audiovisuais (como filmes, documentários, clipes de música, programas de televisão, programas de rádio), obras artísticas, sítios eletrônicos, histórias em quadrinhos, arquivos pessoais, egodocumentos, entre outros. Lidar com um conjunto tão amplo de fontes força os historiadores a ampliar seu escopo de pesquisa, a buscar diálogos com outras áreas de estudo, mas também a discutir o próprio fazer historiográfico, o que leva a questões como a subjetividade do autor e a forma de constituição de sua narrativa.

As dissertações desenvolvidas também são marcadas por uma diversidade de temas, o que dificulta sua categorização. Mesmo correndo o risco que toda classificação acarreta, podemos identificar alguns temas entre os vários que foram orientados nas dissertações nestes dez anos de programa.

Um conjunto significativo destas pesquisas (12 dissertações) trata de questões relacionadas ao tema história da cidade e urbanização. A maioria é constituída de estudos sobre as transformações urbanas ou a ocupação dos espaços públicos de cidades do estado de Santa Catarina, em sua maioria, da capital, Florianópolis. Outro tema aprofundado no programa refere-se às políticas de patrimonialização e ao patrimônio cultural (nove dissertações). Pesquisas sobre migrações, principalmente as de trânsito internacional, também constituem um grupo importante, tratando de questões como as migrações de brasileiros para o exterior, principalmente para os Estados Unidos e o Japão, e igualmente sobre o movimento inverso, de retorno destes migrantes após anos de vida no exterior.

Outro importante conjunto de pesquisas é o das que têm como eixo de discussão os diálogos com a música e a produção imagética. Um total de oito dissertações tem como tema de pesquisa grupos musicais ou artistas e suas produções. Trata-se de grupos de artistas que tiveram papel importante na cultura local em determinada época; também 
que utilizam fotografias e cinema totalizam nove dissertações. Além destes trabalhos, que puderam ser agrupados a partir das fontes, outros agrupamentos, a partir de outros critérios, poderiam ser realizados. Continuando a trabalhar pelo critério de fontes, salientam-se as pesquisas, poucas ainda, que têm enveredado pelo mundo virtual, não somente em busca de facilidades de acesso a documentos digitalizados, mas em busca de novas fontes, produzidas no ambiente virtual e que por ele circulam ou circularam, caso de blogs e redes sociais, a fim de investigar como novas sociabilidades, práticas de consumo e escritas se constituem em tempos de amplo acesso à internet.

Além dos temas citados, muitos outros trabalhos foram produzidos nesta mesma linha, que transitam por outros temas, como comemorações, práticas de leitura e cultura escrita, religiosidade, narrativas sobre o passado, historiografia, gênero, instituições, moda ... O conjunto de temas é bastante amplo, o que, de certa forma, é decorrência da amplitude e da diversidade de interesses desenvolvidos pelos docentes integrantes desta linha. Pode-se, entretanto, afirmar que a abordagem teórico-metodológica das dissertações converge para os estudos da contemporaneidade em que a escolha do vetor tempo presente vem dar espessura aos estudos próprios da história, aqui consubstanciados em duas ações: 1 - certa maneira de pensar a História do Tempo Presente e 2 - percursos para materializar possibilidades de consolidação do PPGH/UDESC.

\section{1 "Certa maneira de pensar a História do Tempo Presente"}

Henry Rousso (2016, p. 28), em seu livro “A última catástrofe. A história, o presente, o contemporâneo", diz que a obra não pretende ter caráter prescritivo sobre "a melhor maneira de escrever a história" e avisa aos leitores que pretende "simplesmente propor uma reflexão sobre certa maneira de pensar a história do tempo presente". É nesta perspectiva que nós, igualmente, centramos nosso texto. Ele exprime 
práticas e representações sociais, embora admitindo a impossibilidade de uma abrangência total na análise desta produção acadêmica.

A análise da produção discente permitiu considerar, sem pretender exaurir e esgotar a análise, que as dissertações de mestrado, produzidas nas duas linhas de pesquisa no âmbito do Programa de Pós-Graduação em História, colocaram em relevo reflexões e argumentos significativos sobre o tipo de história do tempo presente que se quer escrever em diálogo com os autores que, juntos, foram estruturando o alicerce teórico-metodológico. Em diálogo com Henry Rousso, considera-se a história do tempo presente um domínio da historiografia e não meramente um marco temporalcronológico. Sua singularidade "está em que ela se interessa por um presente que é o seu, em um contexto em que o passado não está nem acabado e nem encerrado, em que o sujeito de sua narrativa é um “ainda aí"” (ROUSSO, 2016, p. 18).

Outro aspecto bastante enfatizado nas dissertações, notadamente nas defendidas entre 2011 e 2016, têm sido as reflexões a partir dos estudos realizados por Paul Ricoeur sobre o tempo histórico. O autor promove um retorno à narrativa problematizada e postula que a experiência humana é afetada e organizada, no tempo, através da intriga moldada pelo historiador. Para Ricoeur (2010, p. XI), “é a narrativa que torna acessível a experiência humana do tempo" e o tempo, por sua vez, só se torna humano pela narrativa. Neste sentido, há uma confluência com os estudos de Koselleck (2006), que se referem ao espaço da experiência de uma geração vivente que gera expectativas, e esta tensão entre experiência e expectativa faz emergir o tempo histórico. Considera Koselleck (2006, p. 309-310) que "o tempo histórico não é apenas uma palavra sem conteúdo, mas também uma grandeza que se modifica com a história" e que "a experiência é o passado atual, aquele no qual acontecimentos foram incorporados e podem ser lembrados". A "a expectativa se realiza no hoje", que "é futuro presente, voltado para o ainda-não, para o não experimentado, para o que apenas pode ser previsto". 
O diálogo com Ricoeur (2010, v. 1), movimentado nas produções do PPGH, também parte do alerta do autor de que "o que a história deseja é, na realidade, mostrar que os acontecimentos não são consequências do acaso" Esta mesma concepção é corroborada pelos estudos de Francois Hartog, para quem:

toda história, seja qual for finalmente seu modo de expressão, pressupõe, remete a, traduz, trai, enaltece ou contradiz uma ou mais experiências do tempo. Com o regime de historicidade, tocamos, dessa forma, em uma das condições de possibilidade da produção de histórias: de acordo com as relações respectivas do presente, do passado e do futuro, determinados tipos de história são possíveis e outros não (HARTOG, 2013, 39).

Além dele, por François Dosse, sobre o acontecimento, a respeito do qual afirma:

Atribuir inteira importância ao vestígio do acontecimento, denotado na evolução flutuante de suas representações e de suas interpretações, significa realizar plenamente a guinada historiográfica que inclui o estudo dos usos e práticas da história no ato de escrever a história (DOSSE, 2013, p. 213).

Assim, podemos considerar que as investigações compreendidas no âmbito da história do tempo presente, na perspectiva viabilizada pelo Programa de Pós-Graduação em História, compreendem as mudanças nas percepções e apropriações do tempo histórico e visam a aglutinar pesquisadores/as capazes de contribuir para um melhor entendimento das trajetórias, e dos eventos nelas inseridos, circunscritas principalmente aos últimos 50 anos, com ênfase nas culturas políticas e sociais que produziram e nas linguagens e identificações que reverberaram em outras diferentes linguagens e distintas identificações. A seleção de discentes, neste ano de 2017, procurou reafirmar as linhas de pesquisa na vertente historiográfica do tempo presente para contemplar as dimensões instituintes fundamentais ${ }^{24}$.

\footnotetext{
${ }^{24}$ A seleção bibliográfica para a seleção discente de 2017 listou a seguinte bibliografia: DOSSE, François. Renascimento do acontecimento. São Paulo: Ed. Da UNESP, 2013; HUYSSEN, Andreas. Culturas do passado-presente: modernismo, artes visuais, políticas da memória. Rio de Janeiro: Contraponto, 2014; KOSELLECK, Reinhart. Estratos do tempo: estudos sobre a História. Rio de Janeiro: Contraponto, Ed. PUC-RJ, 2014; RÉMOND, René. Por uma história política. Rio de Janeiro: Ed. da FGV, 2003; ROUSSO, Henry. A última catástrofe: a história, o presente, o contemporâneo. Rio de Janeiro: Ed. Da FGV, 2016; FICO, Carlos; ARAUJO, Maria Paula; GRIN, Monica (Orgs.). Violência na História: Memória, Trauma e Reparação. Rio de Janeiro: Ponteio, 2013.
} 
Apresentados ao tempo presente como campo de investigação, estes pesquisadores encontraram nas abordagens historiográficas meios para reordenar a profusão de imagens e informações, tanto as difundidas pelos meios de comunicação de massa (que tendem a esvaziar de sentido a temporalidade), quanto as propagadas pela oralidade e pela escrita, além de outras modalidades de expressão que ampliam e adensam o potencial da história como forma de conhecimento.

\subsection{Percursos para materializar possiblidades de consolidação do PPGH/UDESC}

Como forma de marcar a primeira década de criação do Programa de PósGraduação em História/UDESC e dos estudos de história do tempo presente que contemplam sua área de concentração, durante todo o ano de 2016 foram realizadas reuniões do corpo docente e discente para redefinir suas linhas de pesquisa e, ao mesmo tempo, refletir sobre suas perspectivas futuras, como, por exemplo, a realização de eventos e sua participação neles, além de publicações conjuntas e individuais do corpo docente e discente.

Neste sentido, foi aprovada a proposta de criação de uma terceira linha de pesquisa, intitulada Políticas de memória e narrativas históricas ${ }^{25}$, centrada na investigação acerca de como a história do tempo presente é atravessada por mecanismos formais que buscam orientar ou mediar processos sociais de constituição de memórias (chegando a conformar políticas), e por diferentes formas de produção, circulação e agenciamento de narrativas históricas. Neste sentido, a linha está particularmente afinada com estudos sobre: as disputas ou batalhas de memória contemporâneas (também chamadas de "memórias concorrenciais"); as variadas formas de lidar com as memórias traumáticas ou "difíceis" (de modo a envolver, entre outras, as práticas presentes em instituições de aprisionamento/sequestro, assim como suas relações de poder/saber); as reivindicações de ressarcimento simbólico feitas por vítimas de regimes autoritários; as estratégias de consagração de personagens, sítios (urbanos ou rurais) e acervos, públicos ou privados, por meio de instrumentos patrimonializadores, tais como o

\footnotetext{
${ }^{25}$ Compõem a linha os professores Claúdia Mortari, Janice Gonçalves, Maria Teresa Santos Cunha, Rogério Rosa Rodrigues e Viviane Trindade Borges.
} 
tombamento, o registro, o cadastro e o inventário; as narrativas históricas veiculadas em meio impresso, sonoro, fílmico ou videográfico mais diretamente associadas a demandas de memória de grupos sociais e povos historicamente subalternizados.

Com relação à organização de eventos, docentes e discentes do PPGH/UDESC organizam, desde 2011, o Seminário Internacional de História do Tempo Presente ${ }^{26}$, dando visibilidade às pesquisas realizadas. Sua terceira edição está programada para os dias 25 a 27 de outubro de 2017. Nestes seminários, o programa tem recebido pesquisadores internacionais, os quais, em conjunto com os docentes/pesquisadores e discentes nacionais propiciam discussões alentadas na área, seja com conferencistas, como François Dosse e Henry Rousso (franceses), como com Leonor Arfuch e Pablo Pozzi (argentinos), Alexander Freund (canadense) e Gerardo Necoechea Gracia (mexicano). Os simpósios temáticos são indicados e coordenados pelos docentes do programa e visam a contribuir para a consolidação da proposta, assim como a visibilizar as pesquisas desenvolvidas sobre os diferentes temas que são objeto de investigação.

Convém destacar, igualmente, o investimento feito para consolidar o PPGH/UDESC, sob a forma de publicação de livros que divulgam a história do tempo presente ao compartilhar experiências de pesquisas na área através da Revista Tempo e Argumento, editada desde 2009. Os livros editados ${ }^{27}$ aprofundam as reflexões sobre as abordagens da história do tempo presente em diálogo com autores já citados, que integram a bibliografia básica trabalhada em sala de aula e solicitada aos candidatos que, desde 2015, se submetem à seleção do mestrado, e, desde 2014, ao doutorado.

Pela análise sumária deste conjunto de dissertações, pelos investimentos teóricometodológicos e pelas ações efetivas de consolidação da área temática realizadas no âmbito do PPGH/UDESC (seminários internacionais, publicações em vários suportes, etc.), pode-se concluir que os cuidados com a legitimidade epistemológica da área estão sendo tomados sem comprometer o alinhamento da proposta e seu núcleo estruturante. Cabe

\footnotetext{
${ }^{26}$ I Seminário Internacional de História do Tempo Presente (de 7 a 9 de novembro de 2011), II Seminário Internacional (de 13 a 15 de outubro de 2014).

27 Dois livros foram lançados: ROUSSO, Henry. A última catástrofe. A história, o presente, o contemporâneo. Rio de Janeiro: FGV; Florianópolis: UDESC, 2016, e a coletânea que reuniu textos das conferências do evento de 2014: GONÇALVES, Janice (Org.). História do Tempo Presente: oralidade, memória, mídia. Itajaí (SC): Editora Casa Aberta, 2016.
} 
ressaltar que o historiador do tempo presente, por investigar fatos inacabados, é perseguido por um desafio, seja no sentido de "produzir a História de nosso próprio tempo, tentando obter uma reflexão que permita um recuo relativo [...], seja pela necessidade de um manter-se à distância em face do próprio presente, uma tarefa dura" (ROUSSO, 2009, p. 209).

\section{Referências}

AREND, Silvia Maria Fávero. Um país impresso: entre culturas políticas e sociabilidades: revistas semanais, projetos sociais e memória histórica no Brasil (1964-1990). CNPq Edital 14/2011.

BÉDARIDA, François. Tempo presente e presença da história. In: AMADO, Janaína e FERREIRA, Marieta de Moraes (Coords.). Usos \& Abusos da história oral. Rio de Janeiro: FGV, 1996. p. 219-232.

BURKE, Peter. História e teoria social. São Paulo: Editora da UNESP, 2002.

CERTEAU, Michel de. A invenção do cotidiano: artes de fazer. Petrópolis/RJ: Vozes, 1994.

CHAVEAU, Agnès; TÉTART, Philippe (Orgs.). Questões para a história do presente. Bauru/SP: EDUSC, 1999.

DOSSE, François. Renascimento do acontecimento. São Paulo: Editora UNESP, 2013.

FICO, Carlos; ARAÚJO, Maria Paula; GRIN, Monica (Orgs.).Violência na História: Memória, trauma e reparação. Rio de Janeiro: Ponteio, 2013.

FOUCAULT, Michel. Microfísica do Poder. Rio de Janeiro: Graal, 1986.

GONÇALVES, Janice (Org.). História do Tempo Presente: oralidade, memória, mídia. Itajaí (SC): Editora Casa Aberta, 2016.

HARTOG, François. Regimes de historicidade: presentismo e experiências do tempo. Belo Horizonte: Autêntica Editora, 2013.

HOBSBAWM, Eric. Sobre História. São Paulo: Companhia das Letras, 1998. 
HUYSSEN, Andreas. Culturas do passado-presente: modernismo, artes visuais, políticas da memória. Rio de Janeiro: Contraponto, 2014;

JANOTTI, Maria de Lourdes. O livro fontes históricas com fonte. In: PINSKY, Carla Bassanezi (Org.). Fontes Históricas. São Paulo: Contexto, 2005. p. 9-22.

KOSELLECK, Reinhart. Estratos do tempo: estudos sobre História. Rio de Janeiro: Contraponto: PUC-Rio, 2004.

KOSELLECK, Reinhart. Futuro Passado: contirbuição à semântica dos tempos históricos. Rio de Janeiro: Contraponto, Ed. PUC-RJ, 2006.

LOHN, Reinaldo Lindolfo. Um país impresso: revistas semanais, democracia, política e cultura no Brasil (1970-1990). CNPq - Edital 43/2013.

LUCA, Tania Regina de. História dos, nos e por meio dos periódicos. In: PINSKY, Carla Bassanezi (Org.). Fontes históricas. São Paulo: Contexto, 2005. p. 111-153.

RÉMOND, René (Org.). Por uma história política . 2. ed. Rio de Janeiro: FGV, 2003.

ROUSSO, Henry. A última catástrofe: a história, o passado e o contemporâneo. Rio de Janeiro: FGV, 2016.

ROUSSO, Henry. Sobre a história do tempo presente: entrevista com o historiador Henry Rousso. Tempo e Argumento. Florianópolis, v. 1, n. 1, p.201-216, jan./jun. 2009.

RICOEUR, Paul. Tempo e narrativa. 3. t. São Paulo: Editora WMF Martins, 2010.

RICOEUR, Paul. A memória, a história, o esquecimento. Campinas: Editora da UNICAMP, 2007.

SILVA, Cristiani Bereta da. Escrever histórias do tempo presente. Algumas questões e possibilidades. Tempos Históricos. M.C. Rondon, v. 9, p. 257-276, 2. sem. 2006. 
Universidade do Estado de Santa Catarina - UDESC Programa de Pós-Graduação em História - PPGH

Revista Tempo e Argumento Volume 09 - Número 20 - Ano 2017 tempoeargumento@gmail.com 